\title{
Psychological Implications of The Late Phase of COVID- 19 Pandemic among Medical Undergraduates, Attending Clinical Wards Rotations in Tertiary Care Hospitals of Rawalpindi, Pakistan: An Online Survey-Based Study
}

\author{
Arham Ihtesham, Ather Iqbal, Muhammad Sarfraz Khan, Ali Murad Jamal, \\ Shahzaib Maqbool, Waleed Inayat Mohamed, Arslan Kareem, Bilawal Abbas, \\ Hafiz Abu Safian, Haider Mubeen, Arbaz Ahmad
}

\section{ABSTRACT}

COVID-19 is proving to be a double-edged sword for health care professionals. It is not only causing physical malfunctioning but mental suffering among medical undergraduates. This study demonstrates the psychological impact and various predisposing factors causing mental distress. This is a descriptive cross-sectional study involving 157 medical undergraduates of Third, Fourth, and Final year MBBS being trained in tertiary care hospitals of Rawalpindi, Pakistan in September 2020, when the graph of COVID-19 was flattening. Data was collected through a selfdesigned questionnaire for demographic details and DASS-21. The mean and standard deviation was calculated for depression, anxiety, and stress levels. Frequencies and percentages were calculated for the severity of DASS-21 and predisposing factors. Data analysis was done through SPSS. V. 25. Out of 157 students, there were $80(51 \%)$ males and 77 (49\%) females. The mean age was $22.52(\mathrm{SD}=1.60)$. The overall mean score of anxiety was $7.43 \pm 4.53$, depression was $7.75 \pm 4.12$, and stress was $8.15 \pm 4.53$. This study found that the most common reason for stress and anxiety among students attending wards was the fear that they might infect their family members $42(26.8 \%)$, followed by the fear of getting infected themselves 39 (24.8\%). This study doesn't exhibit a significant mental burden of grave concern however, the anxiety level was high among the Third year and depression level was high among Final year students. Fear of infecting family members and contracting the virus themselves were common reasons for distress.

Keywords: Anxiety, COVID-19, depression, stress, wards rotations.

Published Online: October 30, 2020

ISSN: $2593-8339$

DOI: 10.24018 /ejmed.2020.2.5.528

Arham Ihtesham

Rawalpindi Medical University,

Pakistan.

Ather Iqbal

Rawalpindi Medical University,

Pakistan.

Muhammad Sarfraz Khan

Rawalpindi Medical University,

Pakistan.

Ali Murad Jamal

Rawalpindi Medical University,

Pakistan.

Shahzaib Maqbool*

Rawalpindi Medical University,

Pakistan.

(e-mail: hasanshahzaib299@gmail.com)

Waleed Inayat Mohamed

Rawalpindi Medical University,

Pakistan.

Arslan Kareem

Rawalpindi Medical University,

Pakistan.

Bilawal Abbas

Rawalpindi Medical University,

Pakistan.

Hafiz Abu Safian

Rawalpindi Medical University,

Pakistan.

Haider Mubeen

Rawalpindi Medical University,

Pakistan.

Arbaz Ahmad

Rawalpindi Medical University,

Pakistan.

*Corresponding Author

\section{INTRODUCTION}

COVID-19, also known as coronavirus disease in 2019, a wave of uncontrolled destruction that originated in the city of Wuhan, China in late 2019 and spread in the whole world like a bush on fire in no time [1]. On January 30, 2020, it was officially declared as a public health emergency by the World Health Organization (WHO) at an international forum. [2] However, on March 12th, 2020 after a careful assessment it was announced by the world health organization (WHO), that this world is going to face another pandemic. [3] A wide range of clinical spectrum was observed in people tested positive for COVID-19, ranging from asymptomatic carriers to severe acute respiratory syndrome (SARS) and multiorgan failure, [4] however, the most commonly observed symptoms are fever, fatigue, and dry cough. As it is a respiratory tract infection, COVID-19 spreads mainly by respiratory droplets, respiratory 
secretions, and direct contact with an infected person, thus human-to-human transmission is documented as a source of spread for COVID-19 also named as SARS-CoV-2 (severe acute respiratory syndrome-coronavirus-2) [5]. In light of such events, it was imperative to enforce preventive measures among the general population around countries to break the chain of transmission by maintaining social distancing, wearing masks, washing hands, restricting movements, and finally by abiding the restrictions implemented by the local governments [6].

However, every pandemic has its psychological impact in terms of depression, anxiety, stress, and sometimes posttraumatic stress disorder (PTSD) on the mental health of the community facing it [7]. But health care professionals (HCPs) including specialist doctors, house-officers, postgraduate trainees, medical undergraduates, and paramedical staff are the most affected population of the community in such pandemics because they are the only armed forces to fight against deadly pandemics in terms of management of diseased patients. In the given situations multiple factors substantially influence the performance of health care professionals including the fear of contracting the disease, lack of experience to handle such situations, fear of transmitting the virus to family and friends, lack of resources, lack of social support, and finally, poor attitude of the community towards the health care providers [8].

COVID-19, previously known as (SARS-COV) is proving to be a double-edged sword for health care workers as evident from a report showing the statistical analysis form Italy, that in April 2020 a total of 10,000 health care providers were exposed to COVID-19, and 74 deaths were reported, [9-10] similarly it is also affecting the mental health of health care professionals as reported in China where health care workers who were attending COVID-19 patients directly, are reporting the tremendous amount of stress, anxiety and insomnia symptoms as compared to other community workers in China [11-12-13]. Hence, it is a need of time to evaluate and address all those factors responsible for various psychological illnesses among health care professionals and hindering their working capabilities in this pandemic.

In this study, we aimed to evaluate the impact of various psychological parameters i.e. depression, anxiety, and stress on medical undergraduates currently enrolled in clinical curriculum and attending their clinical wards rotations, mostly occupied with COVID-19 patients in three different tertiary care hospitals of Rawalpindi, Pakistan. we also aimed to enumerate the various documented reasons for their apprehension on attending the clinical wards including medicine, surgery, and their sub-specialties in this COVID19 pandemic.

\section{MATERIALS AND MethodS}

\section{A. Study Design and Period}

It is a hospital-based descriptive cross-sectional study conducted in teaching hospitals of Rawalpindi Medical University, Rawalpindi, Pakistan. The study was conducted from 15 September 2020 to 15 October 2020 when the graph of COVID-19 was flattening in Pakistan.

\section{B. Study Population and Study Setting}

The study population included all the medical undergraduates who were currently enrolled in clinical years that consisted of the third year, fourth year and final year medical students performing their wards duties in Tertiary care hospitals of Rawalpindi. They were asked to attend the clinical wards rotations in two major medical specialties medicine and surgery as well as their sub-specialties. All those students who were previously healthy and those who did not contract COVID-19 in past were included. The study was carried out on medical undergraduates of three different teaching hospitals of Rawalpindi Medical University named as Holy Family Hospital (HFH), Rawalpindi, BenazirBhutto Hospital (BBH), Rawalpindi is previously known as Central-Hospital, and District-Headquarter Hospital (DHQ).

\section{Sample Size and Sampling}

A sum of 157 medical undergraduates enrolled in the clinical curriculum were selected based on sample size calculated by the world health organization (WHO) calculator and keeping the confidence level of $95 \%$ and taking 5\% margin of error. A simple random sampling technique was followed while collecting the sample population, hence there was an equal chance for every student to be selected in the study population.

\section{Data Collection and Data Analysis:}

The data collection was done through a carefully structured, self-administered Questionnaire constituted of (1): Demographic details which consisted of gender, age, boarder, non-border, and clinical year of study (2): English version of the Depression Anxiety Stress Scale -21 (DASS21). DASS-21 is a 21 -item self-report validated instrument designated to measure the three related negative emotional states, which are: depression, anxiety, and stress having Cronbach's alpha value of $0.83,0.80$, and 0.82 for each subscale of DASS-21 [14,15]. (3): The online form also included various reasons, students thought were predisposing factors for depression, anxiety, and stress while working in clinical wards. The collected data was analyzed using the Statistical package for social science (SPSS) Version 25.0 (IBM Corp, Armonk, NJ). Mean and standard deviation (SD) were calculated for the score of anxiety, stress, and depression. Frequencies and percentages were calculated for the severity of DASS-21 and reasons predisposing students to depression, anxiety, and stress.

\section{RESULTS}

The mean age was $22.52(\mathrm{SD}=1.60)$. Out of 157 students, there were $80(51 \%)$ males and $77(49 \%)$ females. The majority of the students were boarders 85 (54.1\%), while there were $70(44.6 \%)$ non-boarders. The year-wise distribution of students was 48 (30.6\%), 54 (34.4\%), and 55 $(35 \%)$ in the $3^{\text {rd }}$ year, $4^{\text {th }}$ year, and a final year respectively. The overall mean score of anxiety was $7.43 \pm 4.53$, depression was $7.75 \pm 4.12$, and stress was $8.15 \pm 4.53$.

The study found the most common reason for stress and anxiety among medical students attending wards was fear of infecting their family members $42(26.8 \%)$, followed by the fear of getting infected themselves 39 (24.8\%). Table I 
shows the frequency of anxiety, depression, and stress anxiety, and depression among students $(\mathrm{n}=157)$.

among students. Table II shows the reasons for stress,

TABLE I: THE FREQUENCY OF ANXIETY, DEPRESSION, AND STRESS AMONG STUDENTS

\begin{tabular}{|c|c|c|c|c|c|c|c|c|c|}
\hline \multirow[t]{2}{*}{ DASS-21 } & \multicolumn{3}{|c|}{ Depression } & \multicolumn{3}{|c|}{ Anxiety } & \multicolumn{3}{|c|}{ Stress } \\
\hline & $\begin{array}{l}3^{\text {rd }} \text { year } \\
(n=48)\end{array}$ & $\begin{array}{l}4^{\text {th }} \text { year } \\
(n=54)\end{array}$ & $\begin{array}{l}\text { Final year } \\
\quad(n=55)\end{array}$ & $\begin{array}{l}3^{\text {rd }} \text { year } \\
(n=48)\end{array}$ & $\begin{array}{l}4^{\text {th }} \text { year } \\
(n=54)\end{array}$ & $\begin{array}{c}\text { Final } \\
\text { year }(n=55)\end{array}$ & $\begin{array}{c}3^{\text {rd }} \\
\text { year } \\
(n=48)\end{array}$ & $\begin{array}{l}4^{\text {th }} \text { year } \\
(n=54)\end{array}$ & $\begin{array}{l}\text { Final year } \\
\quad(n=55)\end{array}$ \\
\hline Normal & $\begin{array}{c}1 \\
(2.1 \%)\end{array}$ & $\begin{array}{c}3 \\
(5.6 \%)\end{array}$ & $\begin{array}{c}3 \\
(5.5 \%)\end{array}$ & 0 & 0 & 0 & $\begin{array}{c}15 \\
(31.3 \%)\end{array}$ & $\begin{array}{c}18 \\
(33.3 \%)\end{array}$ & $25(45.5 \%)$ \\
\hline Mild & $\begin{array}{c}22 \\
(45.8 \%)\end{array}$ & $14(25.9 \%)$ & $\begin{array}{c}5 \\
(9.1 \%)\end{array}$ & 0 & $\begin{array}{c}4 \\
(7.4 \%)\end{array}$ & $\begin{array}{c}9 \\
(16.4 \%)\end{array}$ & $\begin{array}{c}21 \\
(43.8 \%)\end{array}$ & $\begin{array}{c}16 \\
(29.6 \%)\end{array}$ & $13(23.6 \%)$ \\
\hline Moderate & $\begin{array}{c}24 \\
(50 \%)\end{array}$ & $\begin{array}{c}27 \\
(50 \%)\end{array}$ & $\begin{array}{c}37 \\
(67.3 \%)\end{array}$ & $\begin{array}{c}11 \\
(22.9 \%)\end{array}$ & $\begin{array}{c}22 \\
(40.7 \%)\end{array}$ & $\begin{array}{c}26 \\
(47.3 \%)\end{array}$ & $\begin{array}{c}11 \\
(22.9 \%)\end{array}$ & $20(37 \%)$ & $15(27.3 \%)$ \\
\hline Severe & $\begin{array}{c}1 \\
(2.1 \%)\end{array}$ & $\begin{array}{c}9 \\
(16.7 \%)\end{array}$ & $\begin{array}{c}9 \\
(16.4 \%)\end{array}$ & $\begin{array}{c}26 \\
(54.2 \%)\end{array}$ & $\begin{array}{c}15 \\
(27.8 \%)\end{array}$ & $\begin{array}{c}15 \\
(27.3 \%)\end{array}$ & $1(2.1 \%)$ & 0 & $\begin{array}{c}2 \\
(3.6 \%)\end{array}$ \\
\hline $\begin{array}{c}\text { Extremely } \\
\text { Severe }\end{array}$ & 0 & $\begin{array}{c}1 \\
(1.9 \%)\end{array}$ & $\begin{array}{c}1 \\
(1.8 \%)\end{array}$ & $\begin{array}{c}11 \\
(22.9 \%)\end{array}$ & $\begin{array}{c}13 \\
(24.1 \%)\end{array}$ & $\begin{array}{c}5 \\
(9.1 \%)\end{array}$ & 0 & 0 & 0 \\
\hline Total & $\begin{array}{c}48 \\
(100 \%)\end{array}$ & $\begin{array}{c}54 \\
(100 \%)\end{array}$ & $\begin{array}{c}55 \\
(100 \%)\end{array}$ & $\begin{array}{c}48 \\
(100 \%)\end{array}$ & $\begin{array}{c}54 \\
(100 \%)\end{array}$ & $\begin{array}{c}55 \\
(100 \%)\end{array}$ & $\begin{array}{c}48 \\
(100 \%)\end{array}$ & $\begin{array}{c}54 \\
(100 \%)\end{array}$ & $\begin{array}{c}55 \\
(100 \%)\end{array}$ \\
\hline
\end{tabular}

Note: DASS-21: Depression Anxiety Stress Scale.

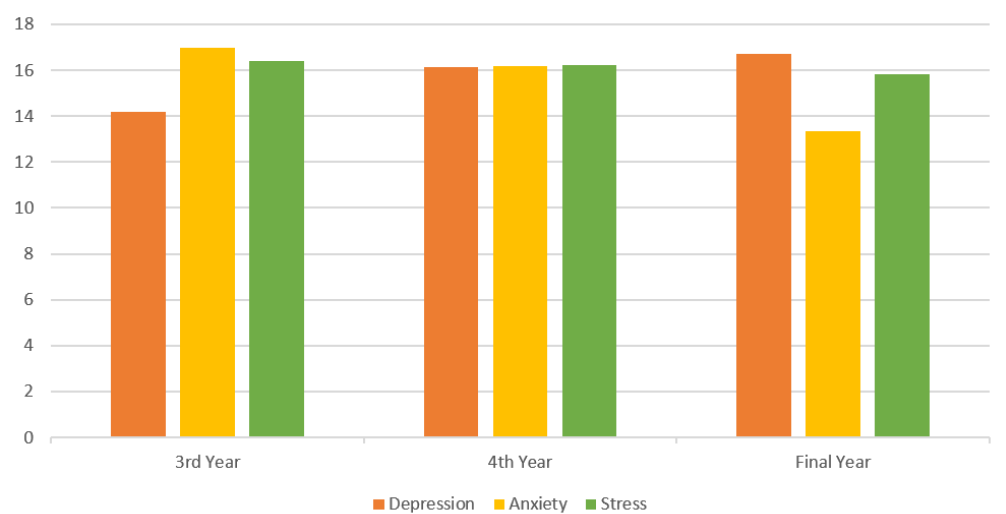

Fig.1. Mean scores of depression, anxiety, and stress distributed year wise. Anxiety level is high among Third-year students while depression level was high among Final year medical undergraduates.

TABLE I: THE REASONS FOR STRESS, ANXIETY, AND DEPRESSION AMONG STUDENTS (N=157)

\begin{tabular}{|c|c|c|c|c|c|c|}
\hline \multirow[t]{2}{*}{ Predisposing Factors of Mental distress } & \multicolumn{2}{|c|}{$\begin{array}{c}3^{\text {rd }} \text { Year } \\
(n=48)\end{array}$} & \multicolumn{2}{|c|}{$4^{\text {th }}$ Year $(n=54)$} & \multicolumn{2}{|c|}{ Final Year $(n=55)$} \\
\hline & $\mathrm{n}$ & $\%$ & $\mathrm{n}$ & $\%$ & $\mathrm{n}$ & $\%$ \\
\hline Possibility of contracting COVID-19 & 7 & 14.6 & 17 & 31.5 & 15 & 27.3 \\
\hline Increased workload & 4 & 8.3 & 4 & 7.4 & 7 & 12.7 \\
\hline Possibility of infecting their family & 12 & 25.0 & 11 & 20.4 & 19 & 34.5 \\
\hline Lack of PPE in hospitals* & 9 & 18.8 & 5 & 9.3 & 4 & 7.3 \\
\hline Lack of security & 4 & 8.3 & 3 & 5.6 & 4 & 7.3 \\
\hline Total & 48 & 100.0 & 54 & 100.0 & 55 & 100.0 \\
\hline
\end{tabular}

*PPE: Personal Protection Equipment.

*SOP: Standard Operating Procedures.

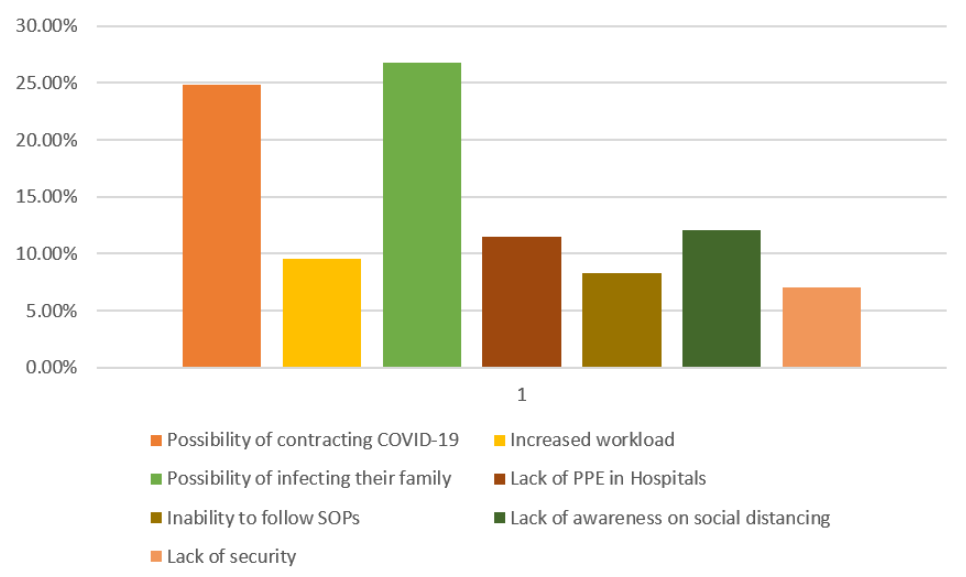

Fig. 2. Showing the overall percentages of reasons predisposing medical undergraduates towards depression, anxiety, and stress during the COVID-19 pandemic. 


\section{DISCUSSION}

The novel coronavirus diseases (COVID-19) not only causing physical implications, but the mental burden is also a common finding among medical professionals including medical undergraduates as well. Medical schools of many countries are promoting their Final semester's students for increasing their manpower to fight against the dreadful COVID-19 [16]. However, due to lack of experience, lack of resources in resource-poor countries, lack of social support, and importantly the fear of getting infected by (SARS-CoV-2) is considered a potent factor that can aggravate distress level among medical students.

In this study, we tried to find the depression, anxiety, and stress levels among medical students currently attending clinical wards in medicine and surgical specialties and reasons causing depression, anxiety, and stress. However, to our surprise, our results were inconsistent with the results from other studies conducted worldwide that showed increased depression, anxiety, and stress levels among health care professionals including medical undergraduates and other paramedical staff. In this study, the overall mean score for depression is $7.43(\mathrm{SD}=4.53)$, for anxiety is 7.75 $(\mathrm{SD}=4.12)$ and the mean value for stress comes to be 8.15 $(\mathrm{SD}=4.53)$ that is lesser than a similar study conducted in Pakistan with the mean value for depression to be 18.12 $(\mathrm{SD}=10.0)$, for anxiety $19.01 \quad(\mathrm{SD}=9.2)$, and stress 20.12 $(\mathrm{SD}=12.0)$ [17]. The possible reason for this major difference in mean values could be the difference in the time frame when these two studies were conducted. The abovementioned study was conducted during May 2020 when the number of positive cases was on the rise in Pakistan and health care professionals were in direct contact with COVID-19 patients. However, our study was conducted in September when the disease burden was less, and the number of positive cases was declining and the disease curve was about to flatten.

A study conducted in Pakistan in June 2020 didn't show a significant association of medical undergraduates and depression, anxiety, and stress. That study also didn't depict any sort of mental health burden among medical undergraduates, and so, it is inconsistent with our study. [18] In the year of study-wise distribution, the mean anxiety and stress level were high among Third-year medical students as compared to Fourth and Final year as shown by statistics, this is justifiable by because of lack of skills, expertise, and particularly newly induction in clinical curriculum play its role in these circumstances. However, the Mean depression level was high among final year students that could be due to increased work-load in terms of clinical and theoretical perspective [19] and COVID-19 could be an incremental factor towards high depression in this condition.

In this study, we also tried to find out the possible reasons for depression, anxiety, and stress levels among medical students working in tertiary care hospitals of Rawalpindi. Much of the documented reasons were similar to many studies conducted worldwide. Some of the documented reasons were fear of contracting COVID-19, chances of spreading the virus to family and friends, lack of awareness among the population, negligence in following the SOPs, and lack of security, and resources in Hospitals. A similar study conducted in Karachi, Pakistan also recorded the same reasons for distress among health care professionals, validating our study showing that much of the students were concerned about the transmission of the virus to their families and the second most common reason was fear of getting infected with COVID-19. On one point, the abovementioned study is validating our findings, and on the other hand, the prevalence of other reasons including lack of security, lack of PPE, and lack of awareness was higher in our study as compared to the previous one [17].

Novelty does exist in our study in terms of the association between variables because as per our knowledge, many studies conducted on mental health-related to COVID-19 nationally and internationally emphasized greatly on the mental health of either the general population or only health care specialist excluding the medical students who were also performing their wards duties. In our study, we tried to classify depression, anxiety, and stress levels against the year of study, and similarly, various documented reasons for mental distress were also plotted against the year of study. But to our surprise, we did not find a significant mental health burden in our study population however, a dire risk of getting mental health illnesses does exist in medical undergraduates that need to be fixed within full capacity by competent authorities.

\section{CONCLUSION}

This study was conducted in September 2020 when the COVD-19 graph was flattening, to find the psychological implications of the COVID-19 pandemic among medical students undertaking training in wards. Our goal was to detect depression, anxiety, and stress levels among medical undergraduates but to our surprise, no significant mental health burden was observed among all three years of study. However, the level of anxiety was higher in Third-year students as compared to the Fourth and Final year but depression level was high among Final year students. The most common documented reason for mental distress was fear of infecting their family members and secondly fear of getting infected themselves though the prevalence of other reasons was also on the higher side as compared to other studies conducted in Pakistan.

\section{ACKNOWLEDGMENT}

We acknowledged all the participants of our study who participated in our study and we also acknowledge all our friends who helped us in data collection.

\section{CONFLICT OF INTEREST}

All authors declare that they have no conflict of interest. 


\section{REFERENCES}

[1] Wang C, Horby PW, Hayden FG, Gao GF. A novel coronavirus outbreak of global health concern. Lancet 2020; 395: 470-73.

[2] World Health Organization. Statement on the second meeting of the International Health Regulations (2005) Emergency Committee regarding the outbreak of novel coronavirus (201nCoV). Jan 30 , 2020. https://bit.ly/2zc56Vk (accessed May 2020).

[3] World Health Organization. Novel coronavirus (2019-nCoV) situation reports. (2020). Accessed: July 3,2020: https://www.who.int/docs/default source/coronaviruse/situationreports/20200607-covid-19-sitrep-139.pdf?sfvrsn=79dc6d.

[4] Singhal T. A review of Coronavirus Disease-2019 (CoViD-19). Indian J Ped 2020; 87: 281-6.

[5] Lee PI, Hsueh PR. Emerging threats from zoonotic coronavirusesfrom SARS and MERS to 2019-nCoV. J Microbial Immunol Infect. 2020 Jun;53(3):365-367. doi: 10.1016/j.jmii.2020.02.001. Epub 2020 Feb 4. PMID: 32035811; PMCID: PMC7102579.

[6] Wilder-Smith A, Freedman DO: Isolation, quarantine, social distancing and community containment: pivotal role for old-style public health measures in the novel coronavirus (2019-nCoV) outbreak. J Travel Med. 2020, 27: taaa020. 10.1093/jtm/taaa020.

[7] Lipley, N. Covid-19: Not a 'Mental Health Crisis', Healthcare Experts Warn. Available online: https://rcni.com/nursingstandard/newsroom/news/COVID-19-not-a-mental-health-crisishealthcareexperts-warn-159611 (accessed on 17 April 2020).

[8] Shigemura J, Ursano RJ, Morganstein JC, Kurosawa M, Benedek DM: Public responses to the novel 2019 coronavirus $(2019-\mathrm{nCoV})$ in Japan: mental health consequences and target populations. Psychiatry Clin Neurosci. 2020, 74:281-282. 10.1111/pcn.12988.

[9] Regly E. Italian doctors' fatalities reach tragic levels as they fight COVID-19 in overburdened hospitals. The Globe and Mail. 2020; https://www.theglobeandmail.com/world/article-italian-doctorsfatalities-reach-tragiclevels-as-they-fight-covid-1/.

[10] Chen Q, Quan B, Li X, Gao G, Zheng W, Zhang J, et al. A report of clinical diagnosis and treatment of nine cases of coronavirus disease 2019. J Med Virol. 2020.

[11] Lai, J.; Ma, S.; Wang, Y.; Cai, Z.; Hu, J.; Wei, N.; Wu, J.; Du, H.; Chen, T.; Li, R.; et al. Factors associated with mental health outcomes among health care workers exposed to coronavirus disease 2019. JAMA Netw. Open 2020, 3, e203976.

[12] Lu, W.; Wang, H.; Lin, Y.; Li, L. Psychological status of medical workforce during the COVID-19 pandemic: A cross-sectional study. Psychiatry Res. 2020, 288, 112936.

[13] Zhang, W.R.; Wang, K.; Yin, L.; Zhao, W.F.; Xue, Q.; Peng, M.; Min, B.Q.; Tian, Q.; Leng, H.X.; Du, J.L.; et al. Mental Health and Psychosocial Problems of Medical Health Workers during the COVID-19 Epidemic in China. Psychother. Psychosom. 2020, 1-9.

[14] Chan RC, Xu T, Huang J, Wang Y, Zhao Q, Shum DH, et al. Extending the utility of the depression anxiety stress scale by examining its psychometric properties in Chinese settings. Psychiatry Res. 2012;200(2-3):879-83.

[15] Wang K, Shi HS, Geng FL, Zou LQ, Tan SP, Wang Y, et al. Crosscultural validation of the depression anxiety stress Scale-21 in China. Psycho Assess.2016;28(5): e88-e100.

[16] Li Y, Wang Y, Jiang J, Valdimarsdottri UA, Fall K, Fang F, Song H, Lu D, Zhang W (2020). Psychological distress among health professional students during the COVID-19 outbreak. Psychological Medicine 1-3. https://doi.org/10.1017/ S0033291720001555.

[17] Sandesh R, Shahid W, Dev K, et al. (July 02, 2020) Impact of COVID-19 on the Mental Health of Healthcare Professionals in Pakistan. Cureus 12(7): e8974. DOI 10.7759/cureus.8974.

[18] Muhammad Alfareed Zafar S, Junaid Tahir M, Malik M, Irfan Malik M, Kamal Akhtar F, Ghazala R. Awareness, anxiety, and depression in healthcare professionals, medical students, and general population of Pakistan during COVID-19 Pandemic: A cross sectional online survey. MEd J Islam Repub Iran. 2020(6 Oct); 34:131. https://doi.org/10.34171/mjiri.34.131.

[19] Baldassin S, Alves TC, de Andrade AG, Nogueira Martins LA. The characteristics of depressive symptoms in medical students during medical education and training: a cross-sectional study. BMC Med Educ. 2008; 8:60.

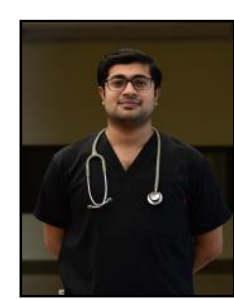

\section{Shahzaib Maqbool}

Palce and date of birth:

Khanewal, Pakistan - 23-7-1995.

Educational background:

B.Sc (english), Final year MBBS, Rawalpindi Medical University Rawalpindi, Pakistan.

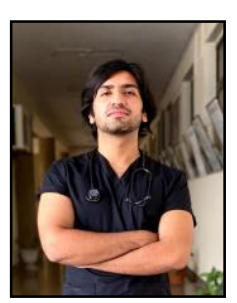

\section{Arham ihtesham}

Place and date of birth

Sahiwal, Pakistan - 10-08-1996

Educational background:

Final year MBBS, Rawalpindi Medical University, Rawalpindi, Pakistan.

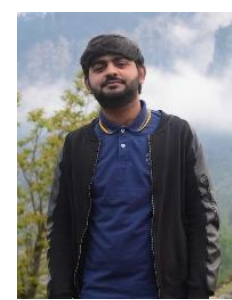

\section{Ather Iqbal}

Place and date of birth:

Multan, Pakistan - 12-07-1995

Educational Background:

Final year MBBS, Rawalpindi Medical University, Rawalpindi, Pakistan.

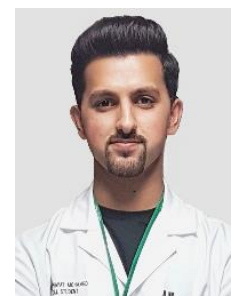

\section{Waleed Inayat Mohamed}

Place and date of birth:

Riffa, Bahrain - 29-08-1997

Educational Background:

B.Sc (english), Final year MBBS, Rawalpindi Medical University, Rawalpindi, Pakistan. 